Proceedings

\title{
Development of Novel API-ILs for the Optimization of Anti-Alzheimer Drugs ${ }^{\dagger}$
}

\author{
Belén Tornero, Verónica Fernández-Stefanuto, Emilia Tojo, Pedro Besada and Carmen Terán * \\ Departamento de Química Orgánica and Instituto de Investigación Sanitaria Galicia Sur (IISGS), \\ Universidade de Vigo, 36310 Vigo, Spain; belentornerofernandez@gamil.com (B.T.); \\ vefernandez@uvigo.es (V.F.-S.); etojo@uvigo.es (E.T.); pbes@uvigo.es (P.B.) \\ * Correspondence: mcteran@uvigo.es; Tel.: +34-986-812-276 \\ + Presented at the 22nd International Electronic Conference on Synthetic Organic Chemistry, 15 November- \\ 15 December 2018; Available Online: https://sciforum.net/conference/ecsoc-22.
}

Published: 14 November 2018

\begin{abstract}
The current treatment of Alzheimer's disease (AD) is mainly focused on enhancing the cholinergic neurotransmission by means of acetylcholinesterase inhibitors (AChEIs). Therefore, there is a growing interest in the development of novel AChEIs. New drugs should not only be able to inhibit the enzyme but also to show optimal parameters of solubility and permeability, since they affect drug bioavailability. Considering the potential advantages of transforming active pharmaceutical ingredients (APIs) into ionic liquids (ILs), five API-ILs derived from two AChEIs, tacrine and a donepezil analogue, were synthesized. The water solubility of these novel API-ILs was analyzed.
\end{abstract}

Keywords: ionic liquids; active pharmaceutical ingredients; acetylcholinesterase inhibitors; phthalazinone scaffold; water solubility

\section{Introduction}

Alzheimer's disease (AD) represents the most frequent form of dementia worldwide [1]. Currently, the treatment of this neurodegenerative disorder is focused on regulating neurotransmitters signaling by using acetylcholinesterase inhibitors (AChEIs) and N-methyl-Daspartic acid (NMDA) glutamate receptor antagonists. Four of the five drugs that have been approved by the U.S. Food and Drug Administration (FDA) for AD are AChEIs, tacrine being the first commercialized and donepezil the most recent, and also the most effective (Figure 1). In addition, studies performed in the last decades have highlighted the role of the AChE enzyme and cholinergic system on $\mathrm{A} \beta$ plaques deposition and modulation of regional brain blood flow [2,3], respectively, contributing to the growing interest in AChEIs.
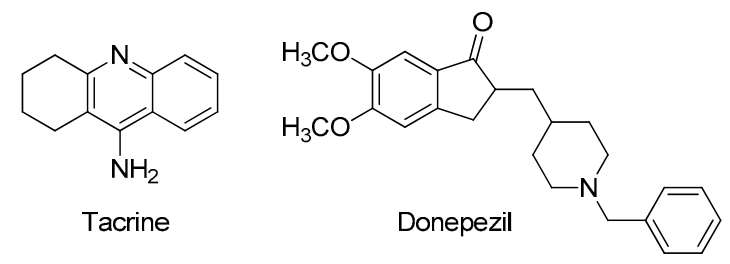

Figure 1. Structure of two representative acetylcholinesterase inhibitors (AChEIs).

Donepezil structure is considered a good starting point for the development of new AChEIs derived from several heterocyclic scaffolds, among them indole (1), pyridazine (2), benzoisoxazole 
(3), or phthalazinone (4) $[4,5]$ (Figure 2). Many of these donepezil analogues display potent AChE inhibition in vitro, being less effective in vivo.

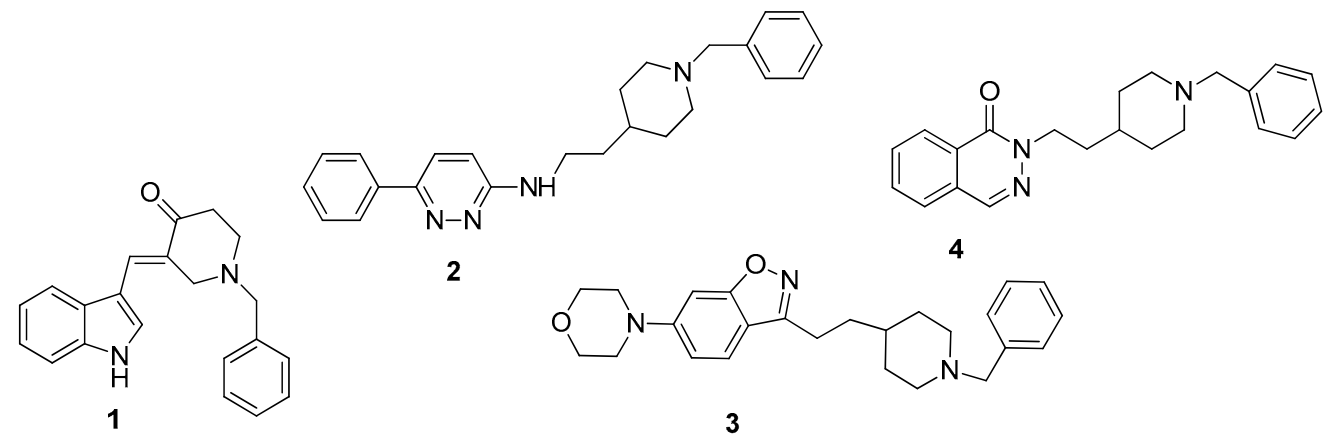

Figure 2. Chemical structure of compounds 1-4, designed as donepezil analogues.

New drugs should not only be able to inhibit the AChE enzyme but also to show optimal parameters of solubility and permeability across cellular membranes, since they affect bioavailability. Overcoming these limitations is a challenge for the pharmaceutical industry. Traditionally, the most common strategy used to increase the solubility of an active pharmaceutical ingredient (API) has been to convert it into a salt. Considering the interesting properties of ionic liquids (ILs), organic salts which are liquid below $100^{\circ} \mathrm{C}$, it is not surprising that in recent years they have triggered the attention of biomedical researchers, both as catalysts or solvents for drugs synthesis [6], and as potential components for the formulations of drugs [7].

Inspired by this idea, as a continuation of our studies on AChEIs [5], with this work we are looking forward to increase the in vivo effectiveness of selected APIs, such as tacrine, a very attractive AChEI because of the numerous modifications that its structure admits, and the donepezil analogue 4 , with in vitro $\mathrm{IC}_{50}$ values in the $\mu \mathrm{M}$ range but inactive in vivo, transforming them into ILs, in order to get better water solubility properties. The different counterions to form the new API-ILs were chosen aiming for high biocompatibility, low toxicity and high water solubility.

\section{Materials and Methods}

Chemical reactants and solvents were purchased from commercial sources and used without further purification. The solvents were distilled and dried according to standard procedures. The glass material employed in the synthetic reactions was dried in an oven at $60{ }^{\circ} \mathrm{C}$ for $24 \mathrm{~h}$ before use. The evolution of the reactions was monitored by thin layer chromatography (TLC) employing silicagel sheets (Merck, TLC Silica gel $60 \mathrm{~F}_{254}$ ). Different mixtures of Hex/AcOEt or AcOEt/MeOH were employed as eluent. Spectroscopic data were provided by the Center of Scientific-Technological Support to Research (CACTI) of the University of Vigo. ${ }^{1} \mathrm{H}$ and ${ }^{13} \mathrm{C}$ NMR spectra were recorded on a BRUKER ARX400 instrument, using TMS as internal standard and $\mathrm{CDCl}_{3}, \mathrm{DMSO}-\mathrm{d}_{6}$ or $\mathrm{CD}_{3} \mathrm{OD}$ as solvents. Mass spectra were recorded by using a Bruker microTOF focus spectrometer.

\section{Results and Discussion}

\subsection{Chemistry}

Tacrine is commercially available as a hydrochloride salt, while compound 4 was synthesized from phthalazinone (5) in four steps [5] following the strategy displayed in Scheme 1. The synthetic sequence involves the N-alkylation of 5 with 4-bromoethyl-N-Boc-piperidine, obtained from the corresponding alcohol precursor, followed by removing of the N-Boc protecting group and subsequent inclusion of benzyl fragment into the piperidine nitrogen. 


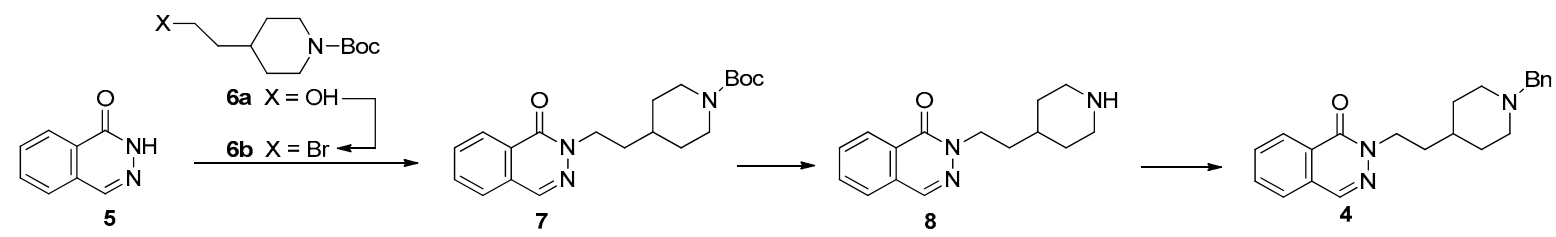

Scheme 1. Synthetic strategy followed to obtain compound 4.

Four new API-ILs were synthesized from tacrine (Scheme 2). Tacrine base was firstly obtained by treatment of the commercial hydrochloride with aqueous $\mathrm{NaOH}$ and then it was treated with the corresponding acid in ethanol at room temperature to provide the desired salt.<smiles>Nc1c2c(nc3ccccc13)CCCC2</smiles><smiles>O[Mg]O</smiles><smiles>Nc1c2c(nc3ccccc13)CCCC2</smiles>

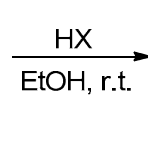<smiles>[X]c1cccc2nc3c(c(N)c12)CCCC3</smiles>

$[\mathrm{Tac}][\mathrm{X}] \mathrm{g}$

9a $[\mathrm{X}]=[\mathrm{TsO}] ; 9 \mathrm{~b}[\mathrm{X}]=\left[\mathrm{CH}_{3} \mathrm{SO}_{3}\right]$

9c $[\mathrm{X}]=[\mathrm{Gly}] ;$ 9d $[\mathrm{X}]=[\mathrm{Sac}]$

Scheme 2. General synthesis of tacrine based active pharmaceutical ingredient-ionic liquids (API-ILs).

The acids selected to react with tacrine were p-toluensulfonic acid, methanesulfonic acid, glycolic acid and saccharin. All them were chosen taking into account the solubility, activity and toxicity data previously described for other analogue salts containing these anions (Figure 3).

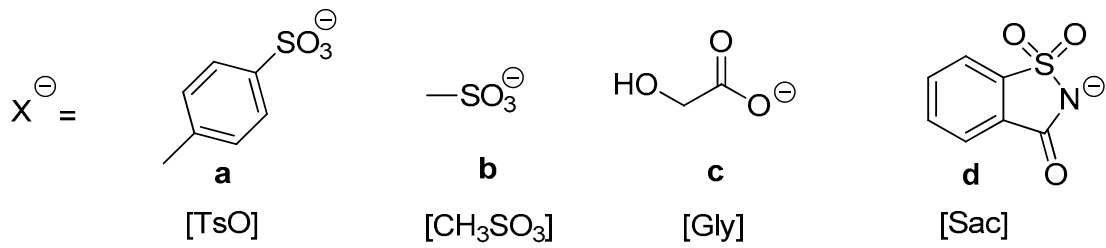

Figure 3. Anions included in the synthesized API-Ils.

In a similar way, another new API-IL was synthesized from the donepezil analogue 4 and methanesulfonic acid (compound 10, Figure 4). Due to the good properties previously observed for the tacrine salt derived from mesylate, this was the anion selected.

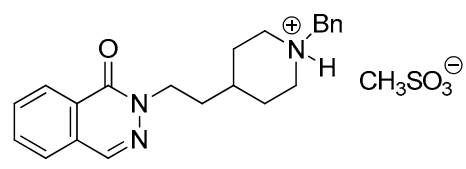

$10\left[\right.$ Donea] $\left[\mathrm{CH}_{3} \mathrm{SO}_{3}\right]$

Figure 4. Structure of the donepezil analogue based API-IL.

The structures of all the new synthesized salts were confirmed by ${ }^{1} \mathrm{H}$ and ${ }^{13} \mathrm{C}$ NMR spectroscopy as well as low and/or high mass spectrometry. Two of the five synthesized API-ILs were found to be liquids at room temperature and both were derived from mesylate.

\subsection{Solubility Test}

A solubility test in water was carried out with the five synthesized salts. Thus, to a known amount of salt, water was added drop by drop (50 $\mu \mathrm{L}$ each) until completely dissolved. The concentrations of the obtained solutions $(\mathrm{mg} / \mathrm{mL})$ were then calculated to give the results shown in Table 1 . As it can be seen, the water solubility observed for [Tac][MeSO${ }_{3}$ ( $(9 \mathbf{b})$ and [Tac][Gly] (9c) was 
considerably higher than the solubility from the commercial salt, tacrine hydrochloride. However, compounds [Tac][TsO] (9a) and [Tac][Sac] (9d) showed a decrease in the value of solubility in comparison with the salt commercially available. In addition, the API-IL derived from donepezil analogue 4, [Donea] [MeSO 3 ] (10), showed a favorable water solubility, in contrast to compound 4, which is completely insoluble in water.

Table 1. Solubility in water of the synthesized API-ILs.

\begin{tabular}{cccc}
\hline API-IL & State at r.t. & Water Solubility of API-IL ${ }^{{ }^{1}}$ & Water Solubility of API $^{\mathbf{1}^{1}}$ \\
\hline$[\mathrm{Tac}][\mathrm{TsO}]$ & Solid & 4 & \\
{$[\mathrm{Tac}]\left[\mathrm{CH}_{3} \mathrm{SO}_{3}\right]$} & liquid & 700 & 100 \\
{$[\mathrm{Tac}][\mathrm{Gly}]$} & Solid & 800 & Tacrine $\mathrm{HCl}$ \\
{$[\mathrm{Tac}][\mathrm{Sac}]$} & Solid & 2 & \\
\hline$[$ Donea $]\left[\mathrm{CH}_{3} \mathrm{SO}_{3}\right]$ & Liquid & 23 & Insoluble Compound $\mathbf{4}$ \\
\hline & &
\end{tabular}

Author Contributions: B.T. and V.F.-S. performed the experiments and analyzed the data; P.B. participated in the synthesis of compound 4; E.T. and C.T. designed the proposed structures and supervised the experiments and results; C.T. performed writing-original draft preparation. All authors contributed to writing the proceeding.

Funding: We acknowledge the Xunta de Galicia (ED431D 2017/06) for financial support.

Acknowledgments: We gratefully acknowledge support from CACTI of the University of Vigo for the acquisition of spectroscopic data.

Conflicts of Interest: The authors declare no conflict of interest.

\section{References}

1. Alzheimer's Association. 2018 Alzheimer's disease facts and figures. Alzheimers Dementia 2018, 14, 367-429, doi:10.1016/j.jalz.2018.02.001.

2. De Ferrari, G.V.; Canales, M.A.; Shin, I.; Weiner, L.; Silman, I.; Inestrosa, N.C. A structural motif of acetylcholinesterase that promotes amyloid $\beta$-peptide fibril formation. Biochemistry 2001, 40, 10447-10457, doi:10.1021/bi0101392.

3. Lane, R.M.; Kivipelto, M.; Greig, N.H. Acetylcholinesterase and its inhibition in Alzheimer disease. Clin. Neuropharmacol. 2004, 27, 141-149, PMID: 15190239.

4. Rodrigues Simões, M.C.; Pereira Dias Villegas, F.; Soares Moreira, M.; De Freitas Silva, M.; Máximo Riquel, M.; Mattos da Rosa, P.; Rosa Castelli, M.; Henrique dos Santos, M.; Gomes Soares, M.; Villegas, C. Donepezil: An important prototype to the design of new drug candidates for Alzheimer's disease. Mini Rev. Med. Chem. 2014, 14, 2-19, PMID: 24251806.

5. Vila, N.; Besada, P.; Viña, D.; Sturlese, M.; Moro, S.; Terán, C. Synthesis, biological evaluation and molecular modeling studies of phthalazin-1(2H)-one derivatives as novel cholinesterase inhibitors. RSC Adv. 2016, 6, 46170-46185, doi:10.1039/C6RA03841G.

6. Welton, T. Room-temperature ionic liquids. Solvents for synthesis and catalysis. Chem. Rev. 1999, 99, 20712084, doi:10.1021/cr980032t.

7. Egorova, K.; Gordeev, E.; Ananikov, V. Biological activity of ionic liquids and their application in pharmaceutics and medicine. Chem. Rev. 2017, 117, 7132-7189, doi:10.1021/acs.chemrev.6b00562. 